\title{
Diet and physical activity in the self-management of type 2 diabetes: barriers and facilitators identified by patients and health professionals
}

\author{
Alison O. Booth ${ }^{1}$, Carole Lowis ${ }^{2}$, Moira Dean $^{3}$, Steven J. Hunter ${ }^{4}$ and Michelle C. McKinley ${ }^{5}$ \\ ${ }^{1}$ Lecturer, Institute of Clinical Science, Nutrition and Metabolism Research Group, School of Medicine, Dentistry and \\ Biomedical Science, Queen's University Belfast, Belfast, UK \\ ${ }^{2}$ Director, Food and Health Communications, North Yorkshire, UK \\ ${ }^{3}$ Lecturer in Consumer Behaviour, Institute of Agri-Food and Land Use, School of Biological Sciences, Queen's \\ University Belfast, Belfast, UK \\ ${ }^{4}$ Consultant Physician, Regional Centre for Endocrinology and Diabetes, Belfast Health and Social Care Trust, Belfast, UK \\ ${ }^{5}$ Senior Lecturer (Nutrition), Nutrition and Metabolism Research Group, School of Medicine, Dentistry and Biomedical \\ Science, Queen's University Belfast, Belfast, UK
}

\begin{abstract}
Aim: To explore the views of individuals recently diagnosed with type 2 diabetes in relation to self-management of dietary intake and physical activity, and to compare these with the views of health professionals (HPs). Background: Diabetes education has become a priority area in primary and secondary care, and many education programmes are now embedded within a patient's care package. There are few contemporaneous explorations of patients' views about lifestyle self-management. Such research is vital in order to identify areas that require further support, refinement or enhancement in terms of patient education. Methods: Focus groups were held with patients recently diagnosed with type 2 diabetes ( $n=16,38 \%$ female, aged $45-73$ years). In-depth semi-structured interviews were conducted with HPs $(n=7)$. Discussions focussed on self-management specifically in relation to making dietary and physical activity changes. All discussions were tape recorded, transcribed and analysed by emergent themes analysis using NVivo to manage the coded data. Findings: Barriers were divided into six main categories: difficulty changing well-established habits, negative perception of the 'new' or recommended regimen, barriers relating to social circumstances, lack of knowledge and understanding, lack of motivation and barriers relating to the practicalities of making lifestyle changes. HPs generally echoed the views of patients. In conclusion, even against a background of diabetes education, recently diagnosed patients with type 2 diabetes discussed a wide range of barriers to self-management of diet and physical activity. The findings could help to provide HPs with a deeper understanding of the needs of recently diagnosed patients and may help refine current diabetes education activities and inform the development of educational resources.
\end{abstract}

Key words: barriers; diet; facilitators; focus groups; physical activity; type 2 diabetes

Received 5 December 2011; revised 23 July 2012; accepted 8 August 2012;

first published online 1 November 2012

Correspondence to: Dr Alison O. Booth, Institute of Clinical Science, Nutrition and Metabolism Research Group, Centre for Public Health, School of Medicine, Dentistry and Biomedical Sciences, Queen's University Belfast, Block B (1st Floor), Grosvenor Road, Belfast BT12 6BJ, UK. Email: abooth@ dekain.edu.au

\section{Introduction}

Approximately 2.3 million people in the United Kingdom have been diagnosed with type 2 diabetes and this figure is expected to continue to rise 
(Diabetes UK, 2010). Although medication plays a key role in type 2 diabetes self-management, attention to diet and physical activity is also important in order to prevent long-term complications (Kulkarni, 2006; Hayes et al., 2008). According to national clinical guidance in the United Kingdom (National Institute for Health and Clinical Excellence, 2008), structured education is a key priority and should be offered to every person with diabetes and/or their carer at and around the time of diagnosis, with reinforcement and review on an annual basis. Health-care professionals facilitate and support this education; however, the responsibility for lifestyle self-management ultimately rests with the patient and can be difficult to achieve and maintain.

Understanding patient barriers to lifestyle change is essential in order to help prioritise areas for intervention and formulate appropriate education materials or programmes. Most of the qualitative information in this area comes from studies in the United States and Canada (El-Kebbi et al., 1996; Maillet et al., 1996; Sullivan and Joseph 1998; Wang et al., 1999; Savoca and Miller 2001; Dye et al., 2003; Kieffer et al., 2004; Vijan et al., 2005; Devlin et al., 2006; Nagelkerk et al., 2006; Carbone et al., 2007), with few studies in the United Kingdom exploring barriers to dietary change (West and McDowell, 2002; Lawton et al., 2005). In addition, although some studies have explored attitudes and beliefs towards self-management among patients with established type 2 diabetes, few have explored these factors specifically among patients who have been recently diagnosed. In the last 10 years, diabetes education has become a priority area in primary and secondary care and many education programmes are now embedded within patient care packages. Against this background of increased diabetes education, there are few contemporaneous explorations of patient's views about lifestyle self-management. Such research is vital in order to identify areas that require further support, refinement or enhancement in terms of patient education.

The aim of this study was to explore the views of individuals recently diagnosed with type 2 diabetes in relation to the self-management of dietary intake and physical activity. Furthermore, there is some evidence that diabetes educators and health professionals (HPs) may view barriers and diabetes care differently from patients (Pendleton et al., 1987; Shultz et al., 2001;
Woodcock and Kinmonth 2001; Carbone et al., 2007), and health-care providers may be able to identify concerns that patients do not verbalise themselves; therefore, a secondary aim was to elicit the views of health-care providers and compare these views with those of the patients.

\section{Methods}

\section{Overview}

Given the study aims, a narrative qualitative approach was adopted that was operationalised through structured interviews with HPs and focus groups with patients. Patients are no longer regarded as passive recipients of health care. They have become active participants, and narrative methodologies play a valuable role in participatory health research and are increasingly relevant in the current climate of public and patient involvement strategies (Gregory, 2010). Narrative research methodologies serve as a medium for 'getting inside' complex health care and social care behaviours and relationships (Hsu and McCormack, 2012). Narrative data may be acquired through many methods; focus groups were chosen for this study owing to their explicit use of group interaction to produce unique data (Barbour and Kitzinger, 1999) and, thus, their potential to generate data that may not become apparent using other methods. According to Krueger and Casey (2000), the purpose of a focus group is to promote a comfortable atmosphere of disclosure in which people can share their ideas, experiences and attitudes about a topic (Krueger and Casey, 2000). Given the study aim, the interaction between individuals was viewed as potentially being very important in order to fully allow patients to share and discuss their perceptions and experiences of managing the lifestyle aspects of type 2 diabetes. Focus groups with HPs were not possible owing to their busy working schedules; therefore, individual interviews were used. This research was conducted between December 2007 and September 2008.

\section{Recruitment and participants}

A purposive sample of HPs with varied areas of expertise was invited to participate in face-to-face interviews. All were involved in the care of people diagnosed with type 2 diabetes. A hospital 
dietitian, a diabetes specialist nurse and two diabetologists were invited from the Regional Centre for Endocrinology and Diabetes, Royal Victoria Hospital, Belfast, United Kingdom. An academic specialist, a community dietitian and a general practitioner from the local area were also invited. All those invited agreed to participate.

Patients were also purposively sampled; letters of invitation were sent to patients from the Regional Centre for Endocrinology and Diabetes, Royal Victoria Hospital, Belfast, United Kingdom, who had been recently (within the previous 24 months) medically diagnosed with type 2 diabetes. All had completed or partially completed the preliminary diabetes education programme at the hospital, which consists of two half-day group education sessions covering a range of topics related to type 2 diabetes including foot care, eye care, nutrition and exercise. All newly diagnosed type 2 diabetes participants are invited to take part, but not all attend. Sessions are held monthly, following which patients are offered at least one one-to-one visit with the Centre's dietitian (amount varies according to their needs, but they are usually asked to return every six months). This study was approved by the Office for Research Ethics Committees Northern Ireland. A written informed consent was obtained from all participants.

\section{Data collection}

The schedules for the interviews with HPs and focus groups with patients are shown in Table 1 . The schedules were devised based on the existing literature together with input from the research team who reviewed the questions for content validity before data collection. Interview questions for HPs focussed on how patients react to their initial diagnosis, what HPs think patients find easy or difficult about making lifestyle changes, how well patients self-manage their condition and any misconceptions held by patients (Table 1). Each interview was held by the same trained interviewer and lasted for $\sim 30-40 \mathrm{~min}$.

Focus groups were conducted with people who had been recently diagnosed with type 2 diabetes. As detailed in Table 1, questions for discussion were similar to those used in the interviews with HPs. Each focus group lasted for $\sim 1 \mathrm{~h}$ and was conducted in a quiet room within the Regional Centre for Endocrinology and Diabetes facility.
One trained facilitator was responsible for conducting all groups.

\section{Data analysis}

All interviews and focus groups were tape recorded, transcribed verbatim and analysed by emergent themes analysis; A.B. and a second researcher independently developed a coding structure after reading and rereading the transcripts. This was followed by a discussion and comparison of the codes (themes and sub-themes) to verify the validity and reliability of their application; any discrepancies were resolved satisfactorily and the coding framework was then applied to the transcripts using NVivo to manage the coded data (QSR NVivo version 8, QSR International). Given the qualitative nature of the data, findings are reported in broad terms (ie, most, many, several, some and few).

\section{Results}

\section{Sample}

Six focus groups were held with people who had been diagnosed with type 2 diabetes within the previous 24 months ( $n=16$; two to four per group, $38 \%$ female, $60.2 \pm 7.5$ (mean $\pm \mathrm{SD}$ ) years of age). Sixty-nine percent were married, $38 \%$ completed college or technical college and 38\% stated secondary school was their highest level of schooling. Seven HPs were interviewed.

\section{Barriers to lifestyle change}

A number of barriers to lifestyle change were identified and divided into six main categories as shown in Table 2. Most of the barriers discussed related to making dietary changes but a few were specific to physical activity. Many of the dietary barriers were identified by both the HPs and patients.

\section{Difficulties changing well-established habits}

The mean age of participants taking part in the focus groups was $\sim 60$ years; therefore, it is not surprising that a predominant discussion point was the concern about changing longestablished habits.

When you get to your 60 s and 70 s it's so hard to change.

(Female, focus group 2) 
Table 1 Interview schedule for HPs and patients

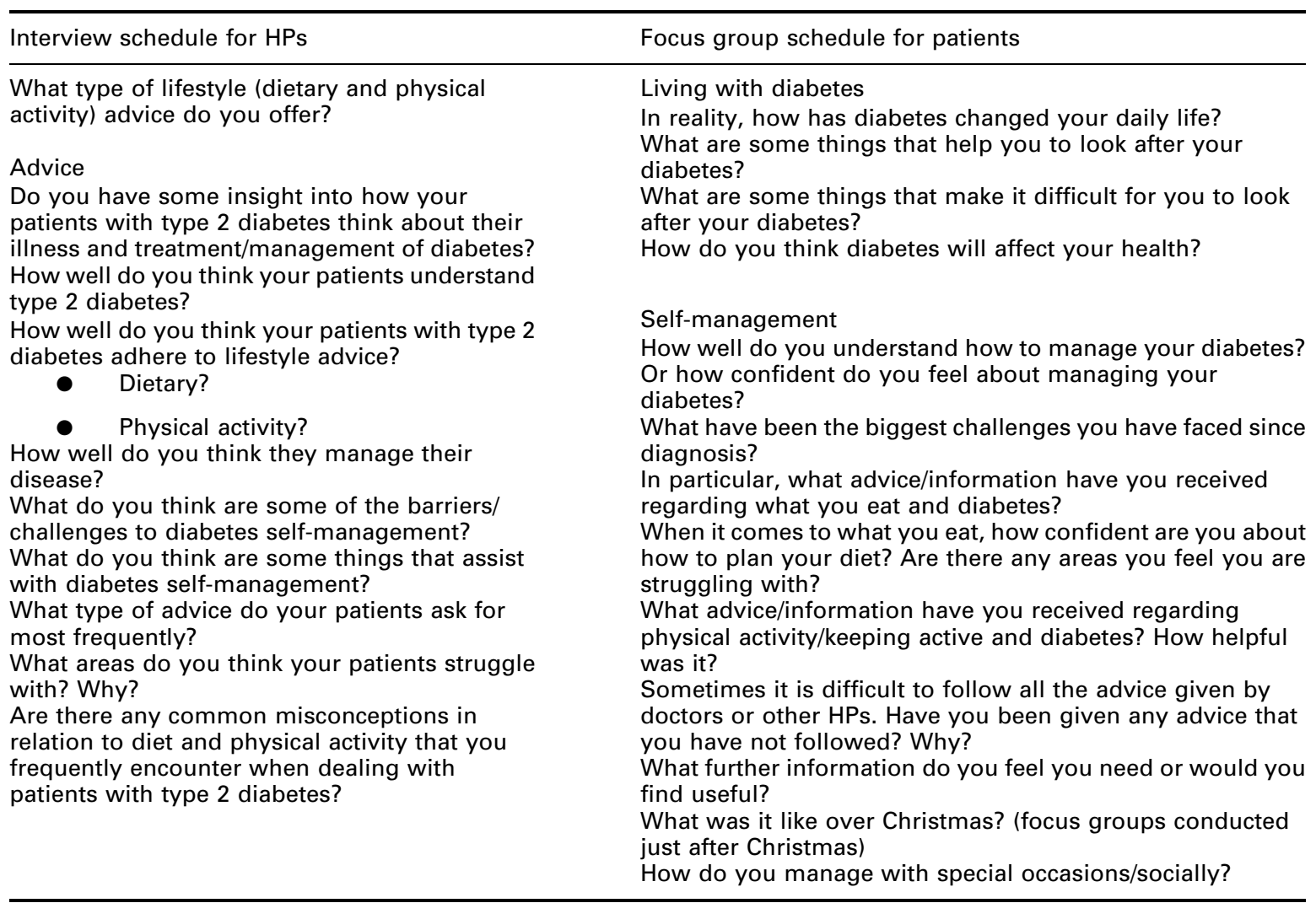

HPs $=$ health professionals.

Coming to nearly the end of life like us you know and try to dictate ... change life you know it is very difficult.

(Male, focus group 5)

The need to make significant dietary changes appeared to be a key concern for patients and was also mentioned by HPs.

The majority would probably be 50 s 60 s even 70 s and you're asking them to break habits of a lifetime so it is very difficult for them you know, diets very difficult for them they have maybe tried to lose weight for years you know and they haven't succeeded so it is difficult.

(Female, Specialist Nurse)

Some routines were seen as cultural habits, for example, binge drinking rather than moderate drinking as recommended, and for some the recommended changes meant a complete change to their dietary pattern, for example, starting to have breakfast when they had never done so before. Others found it difficult to change specific habits.

Like myself, even at school I never had breakfast. I went straight out. I never - and some ways since I came here because the dietitian making the point about eating in the morning - it's only in the past three, four months that I have really forced myself to eat a breakfast in the morning even though some ways I am really not that hungry but I am trying to change my eating routine which was no breakfast.

(Male, focus group 3)

\section{Barriers relating to patients' perception of their 'new' regimen}

Discussions with patients also revealed several negative perceptions towards the 'new' or 
Table 2 Barriers to lifestyle change that emerged from discussions with people recently diagnosed with type 2 diabetes and HPs involved in their care

\begin{tabular}{|c|c|c|}
\hline Barrier & $\begin{array}{l}\text { Representative quotes from the patient } \\
\text { focus groups }\end{array}$ & $\begin{array}{l}\text { Representative quotes from the } \\
\text { interviews with HPs }\end{array}$ \\
\hline $\begin{array}{l}\text { Changing established habits } \\
\text { - Changing lifetime habits } \\
\text { and established dietary } \\
\text { patterns }\end{array}$ & $\begin{array}{l}\text { 'When you get to your } 60 \text { s and } 70 \text { s it's so } \\
\text { hard to change' } \\
\text { 'Coming to nearly the end of life like us } \\
\text { you know and try to dictate ... change life } \\
\text { you know it is very difficult' } \\
\text { 'I left the house in the morning, I never } \\
\text { took a lunch with me, I never even } \\
\text { bought a lunch' } \\
\text { 'Even at school, I never had breakfast' } \\
\text { 'Always had chocolate when working at } \\
\text { the computer' } \\
\text { 'It took me } 3 \text { days to get over that! } \\
\text { [moderate drinking rather than 'binge"']' }\end{array}$ & $\begin{array}{l}\text { 'If they've never had a breakfast or } \\
\text { don't eat regular meals - it's a big } \\
\text { change in eating habits' } \\
\text { 'The majority would probably be } 50 \text { s, } \\
60 \text { s, even } 70 \text { s and you're asking them } \\
\text { to break habits of a lifetime so it is } \\
\text { very difficult for them you know' } \\
\text { 'They've just been eating poor, } \\
\text { unhealthy diets for years' } \\
\text { 'They want to stick with the sort of } \\
\text { things that they were brought up with } \\
\text { cooking' } \\
\text { 'The culture is that you drink on one or } \\
\text { two nights in a week' }\end{array}$ \\
\hline
\end{tabular}

Negative perception of the 'new' regimen

- Not liking recommended foods

Viewing the diet as unappealing and lacking in variety and enjoyment

- Amounts of food recommended; too little or too much

Rigidity of the 'new' routine
'I don't like breakfast cereals all that much' 'I never ever liked fruit so I find it hard to eat fruit'

'It's like a big wrench going from what you normally ate to the likes of fish and fruit and salads and stuff ... it's all stuff that I didn't like'

'I'm talking about brown bread being brown I cannot eat it'

'Its hard to get a variety... because I've been eating the same thing nearly, you know every day but then you get fed up with it'

'You do you get fed up with it you do wheaten bread and wholemeal bread that's your lot'

'What I don't like doing is sticking with the same thing all the time cos I think you get very bored with it and that can hit your motivation [referring to salads]. You get fed up eating that there'

'The only dietary change was cut out all the stuff you enjoy'

'Ice-cream, chocolate biscuits, sugar in my tea - all the usual - all the good stuff' 'Portion control being the thing which hit me between the eyes and that I think if I'm eating healthily I can eat as much as I want - or I used to think that'

'Meat the size of your palm... I struggle with that'

'Salad wouldn't do a man'

'I don't eat 5 pieces of fruit a day. I just can't cope with 5 pieces'

'I'm not really into routine like, but that's part of it, you have to eat at the same time' 'You're too busy working in some ways to worry about it'
'They perceive healthy foods as being boring'

'They have a sort of all or nothing attitude to it when you are trying to say you can still have your treats sometimes - it's getting them to hear what you are saying rather than just honing in the "life's not worth living any more" if they've gotta cut out $X, Y$ and $Z^{\prime}$

'Usually we're asking people to give up things that they enjoy' 
Table 2. Continued

\begin{tabular}{ll}
\hline Barrier & $\begin{array}{l}\text { Representative quotes from the patient } \\
\text { focus groups }\end{array}$ \\
\hline & (Missing lunch) '... my daughter had me \\
& for hours and hours around the shops' \\
'You can't live like a monk ... you can't \\
live on the tight constraints'
\end{tabular}

\section{Social}

- Having to eat differently from family, friends and colleagues

- Shopping/cooking for other people

- Social situations and special occasions, for example, Christmas, weddings, holidays

Lack of knowledge and understanding
'I would need to convert everybody I work and live with as well as myself' 'You have to break everybody else's routine as well as your own ... one of the secretaries would come up with a cup of tea but they'd invariably bring a biscuit with them'

'Well, my daughter - I don't think she fully understands - she likes to cook, but she likes to cook with cream'

'Well, I've got 2 young kids ... if you come home with groceries and there's no sweets, no biscuits in it you get sent straight out again'

'You buy things for other people because you don't want to be restricting them. So I find that then there's temptation in the house - I find that hard'

'Well I find it hard at Christmas .... everybody sitting, everybody eating... I love a wee mince pie' 'There is the temptation thing so I know myself - I know how to keep it under control - now that's slipped since Christmas'

'I was at a wedding and they had pavlova... didn't have anything that would be suitable for me'

'Hotels don't really cater for people with diabetes'

' $Z$ and $X$ downs a bottle of vodka and I'm sitting there with a glass of water - bored to death'

\section{'I don't know what to eat, I don't know what to do' 'Well what can you have for desserts then?'}

'Are you allowed brown fish or are you only allowed white fish?'

'I went to an information session ...but then when you come away it's sorta hard to remember everything'

'You can take a wee bit of cheese the size of a matchbox. That's the only thing I can remember about carbohydrates' 'Just sometimes I want to desperately understand exactly what I am and am not allowed to eat'
Representative quotes from the interviews with HPs
'Their family members are eating a terrible diet and its pretty difficult for them to eat a decent diet if everybody else is eating a bad diet'

'I guess one of the largest [barriers] is who they are living with and who is preparing their food and ... that family members don't want to take the advice on board'

'A woman is maybe used to running a home and puts the kids and everything first'

'(It's) nearly Christmas so how do they handle that and people bringing them sweets and or maybe more and you know more sweety, rich food' 'If they're lonely and their only form of company is going to the pub, well they are not going to change'

'Their knowledge levels were pretty low so some of them didn't know what they should be doing' 'The biggest challenge is just the huge amount of information that they have to assimilate'

'Maybe you give more limited information and there is questionable understanding of it' 
Table 2. Continued

Motivation

Regarding diabetes as a serious condition

Not regarding diabetes as a serious condition

- Lack of short-term consequences

- Lack of success

Medication is sufficient

Practicalities

- Cost of a healthy diet

Access to a healthy diet

- Having other limiting conditions (for exercise) 'it's really scary', 'my concern too you know all of a sudden you're going to end up... losing toes, feet, etcetera, etcetera. You know this is going to happen'

'I feel ok'

'Diabetes doesn't bother me at all - I don't feel any different'

'Doesn't really effect my health much apart from tiredness' 'I am not great at doing what I am told. I have to see the benefit of it and I don' $\mathrm{t}^{\prime}$ 'My blood sugar wasn't coming down and I said that I'm sticking to her diet and everything'

‘ was eating very little... still blood sugar wouldn't come down'

'But sometimes it's frightening when it goes up for no reason'

‘ just started putting... weight on for no apparent reason - it wasn't eating any extra' 'I'Il eat as normal because I'm taking this metformin medicine'

'I've got arthritis you see so I can't stand very long'

'I can't walk because my ankle swells up... I can only go so far'

'(I have a) very bad hip and I can't do as much as I used to'

'I had two major operations over a period of about 2 and a half years... they told me not to stretch or lift anything heavier than 3 pound weight'
'They think that type 2 diabetes is a mild diabetes'

'...they don't think it is as serious as it is - that's the biggest misconception

"it's just a touch of diabetes" you know 'nothing to worry about' 'There's not really many noticeable short-term penalties for some people for not sticking to it'

'There are no immediate short-term gains. It is very difficult to convince them that this is something that needs to be taken seriously because they feel ok' 'They have maybe tried to lose weight for years you know and they haven't succeeded so it is difficult'

'Even if they are doing pretty well with diet ... they sometimes view that as "well the blood sugars going up it must be me, it must be my own failure"'

'They don't really realise how important it is [lifestyle]... and often feel that there's tablets and everything to sort out all their health care' 'Misunderstanding... just how much of looking after diabetes really begins and ends with the patients'

'The expense is a big factor as well healthy eating is not cheap'

'I think there is the perception that eating healthily is more expensive' 'I say one of the barriers would be financial constraint'

'... depend on the van that comes around or corner shops or garage shops' 'They have somebody else doing their shopping or somebody else is providing the meals'

'Lack of ability to cook and prepare nutritious meals'

'A lot of these people, the older people especially, have things of maybe existing cardiac conditions or chest conditions or something like arthritis where they really can't do a lot of exercise'

'I think with the exercise you are dealing with older people and often with co-morbidities and I think it's often difficult for them to get out and exercise'

Primary Health Care Research \& Development 2013; 14: 293-306 
Table 2. Continued

\begin{tabular}{lll}
\hline Barrier & $\begin{array}{l}\text { Representative quotes from the patient } \\
\text { focus groups }\end{array}$ & $\begin{array}{l}\text { Representative quotes from the } \\
\text { interviews with HPs }\end{array}$ \\
\hline $\begin{array}{l}\text { Environmental (for } \\
\text { exercise) }\end{array}$ & $\begin{array}{l}\text { 'It's difficult to go out in rain' } \\
\text { 'Dodging the traffic...no footpaths and } \\
\text { things' }\end{array}$ & $\begin{array}{l}\text { 'Maybe even the people that live in a } \\
\text { country area, I suppose often the } \\
\text { roads are very busy there might be } \\
\text { nowhere easy to go for a walk' }\end{array}$ \\
& $\begin{array}{l}\text { 'I'm a bit reluctant especially in wet } \\
\text { weather and icy weather... there's that } \\
\text { many dips in footpaths now' }\end{array}$ & $\begin{array}{l}\text { 'Maybe at the end of a big day there is } \\
\text { not time for exercise' }\end{array}$ \\
& $\begin{array}{l}\text { 'If I had a river or beach to walk along } \\
\text { every night I would do it - the idea of } \\
\text { walking in around about [local area] the } \\
\text { Falls Road or whatever - it just doesn't } \\
\text { grab me' }\end{array}$ & \\
Il live too far away to actually walk to \\
work'
\end{tabular}

HPs $=$ health professionals.

recommended regimen. Patients highlighted that they felt they were being asked to cut out foods that they found enjoyable in favour of foods they did not like. They perceived the new dietary regimen to be boring and lacking in variety and felt that the required portion control was stark (too small in some cases and too large in others), which was something they would struggle with. They also felt that the recommended diet regimen was too rigid and constrained. When considered together, these factors indicate that recently diagnosed patients view the recommended diet as unappealing and not enjoyable.

The food, going from what you normally eat to fruit all the time you know and fish - it's all stuff that I didn't like. I never had much of it. It's like a big wrench going from what you normally ate on the likes of fish and fruit and salads and stuff.

(Male, focus group 2)

What I don't like doing is sticking with the same thing all the time ... I think you get very bored with it and that can hit your motivation.

(Female, focus group 6)

The fact that patients perceive the recommended dietary regimen as boring and restrictive was also verbalised in discussions with HPs.

'They perceive healthy foods as being boring', 'they have a sort of all or nothing attitude to it when you are trying to say you can still have

Primary Health Care Research \& Development 2013; 14: 293-306 your treats sometimes - it's getting them to hear what you are saying rather than just honing in the "life's not worth living any more" if they've gotta cut out X, Y and Z'.

(Female, Dietitian)

\section{Barriers relating to the social environment in which people live their lives}

Many socially related barriers were discussed by both patients and HPs. The social network in which people live and work presented a challenge as often family or friends or work colleagues were not necessarily mindful of, or sympathetic towards, the needs of the person who had diabetes. For women, there was also an additional problem in that they were generally responsible for shopping and cooking for other people, and often their needs came secondary to the preferences of the other members of the family; inevitably, it seemed that they purchased food preferred by other family members, thus making their food choices at home more difficult. Social occasions in general were highlighted as difficult, again because there was too much temptation on offer and often a lack of healthier or more appropriate choices. The focus groups were conducted around Christmastime and many patients acknowledged that they had difficulty getting back on track afterwards (Table 2).

Even when you say to them I'm not allowed any biscuits they [work colleagues] still come up and they say 'sure one's not going 
to be any harm with a cup of tea' the problem is then you're having 4 or 5 cups of tea during the day - a working day, so you're getting 4 and 5 chocolate biscuits during the day ... and then at home you kinda go out and you say right I'm not going to buy any biscuits and cakes this weekend for the groceries so you come home and the first thing somebody says is 'what sweet stuff did you buy - did you get any biscuits?' so they go out and buy them so it's sitting there.

(Male, focus group 3)

Their family members are eating a terrible diet and it's pretty difficult for them to eat a decent diet if everybody else is eating a bad diet.

(Male, Consultant Physician)

\section{Lack of knowledge and understanding}

HPs commented on the large amounts of information that patients are required to assimilate and did vocalise that knowledge was a barrier to positive change. Patients clearly vocalised a feeling of not being able to process and recall all the information that was provided to them and so they felt adrift.

I went to an information session which was very good went over for one afternoon and one morning but then when you come away it's sorta hard to remember everything, you know.

(Female, focus group 1)

Knowledge levels were pretty low so some of them didn't know what they should be doing.

(Female, Academic Specialist)

This lack of understanding and uncertainty was evident in discussions between participants as they frequently asked each other questions about what foods were suitable or unsuitable for consumption (Table 2). Some of the main areas of confusion related to the following: the concept of carbohydrates, both how much and what type was recommended; fruit consumption in terms of what fruits were or were not allowed and how many portions of fruit should be consumed per day; and sugar versus fat; in general more priority was given to consideration of the sugar content rather than the fat content.

I like yogurts...you have to watch the fat content, you have to watch the sugar content, and I get confused with it so I actually haven't been eating yogurt, which I really like... I just don't know which ones to go for.

(Female, focus group 1)

A critical issue in relation to knowledge and education in general was that some patients felt they received little or no information on what to eat during the initial weeks or months following diagnosis. Some ate small amounts of food due to fear of eating the wrong foods or they did try to make changes themselves only to find they had made unsuitable changes.

(I started having) honey...came here and they were horrified 'my god you can't touch honey you know'.

$$
\text { (Male, focus group 4) }
$$

They (told) me that my blood sugar was far too high and it was dangerous but they didn't do anything for 10 weeks. They told me to try and bring this down to a manageable level...I'm basically not eating because they're sorta saying you know, control it and what not and I was eating very little - eating enough to stay alive but eating very little still blood sugar wouldn't come down.

(Male, focus group 3)

\section{Barriers relating to a lack of motivation}

A general lack of motivation to make lifestyle changes was an important barrier highlighted by both patients and HPs and many factors contributed to this lack of motivation. HPs highlighted that some patients did not view diabetes as a serious condition and therefore did not feel any particular urgency to examine their lifestyle and make appropriate changes. This was not a view expressed by patients; most appeared to be well aware of the long-term consequences of type 2 diabetes and expressed fear about the possibility of becoming ill or developing complications. For some, this fear of the long-term consequences acted as an inducement to change (see section 'Facilitators of lifestyle change' on facilitators below).

My concern too you know all of a sudden you're going to end up...losing toes, feet, etcetera, etcetera. You know this is going to happen.

(Male, focus group 4) 
Other demotivating factors included the lack of short-term consequences, which meant that some individuals had no symptoms and so no incentive to change. Some said they had tried to change their lifestyle but became disillusioned when they had not experienced any benefit, for example, blood glucose remaining high. One participant felt that medication was sufficient to take care of their diabetes and so they did not need to take any action themselves.

Human being is naturally lazy. You can't just you know force yourself you know to eat something you know you don't like... I'll eat as normal because I'm taking this metformin medicine.

$$
\text { (Male, focus group 5) }
$$

\section{Barriers relating to the practicalities of changing behaviour}

Two barriers were clearly discussed in relation to increasing physical activity levels by both the HPs and the patients having other limiting conditions and environmental influences (Table 2). Most of the patients had co-morbidities such as arthritis, and previous major operations that limited their ability to attempt to tolerate increased physical activity. In addition to these physical limitations, poor weather, traffic, safety concerns and lack of pleasant places to walk were among many reported environmental barriers to meeting the activity recommendations.

At different times of the year, weather isn't great so I figure 'oh aye' if I do my exercise but get pneumonia on the way getting me exercise or slip on the ice which again wouldn't do me any favours... I'm a bit reluctant especially in wet weather and icy weather... there's that many dips in footpaths now.

(Female, focus group 6)

I can't walk because my ankle swells up... I can only go so far.

$$
\text { (Male, focus group 3) }
$$

\section{Facilitators of lifestyle change}

In general, factors that facilitated behaviour change were discussed to a much lesser extent compared with barriers to behaviour change; however, several factors that aided motivation or supported behaviour change were evident from discussions. Patients reported that feeling healthier in response to making changes encouraged them to continue and many were motivated by the desire to avoid long-term health consequences or to remain well. Some patients also reported that self-monitoring of blood glucose levels and meeting set targets, such as weight loss, helped keep them motivated and the support of HPs and family members were also raised as important facilitating factors, for example, having a partner that cooks for them. HPs also mentioned setting targets, follow-up visits or additional reviews and the diagnosis itself as being motivators to change.

After the first weeks of cutting out the sugars I felt a lot better - just felt better, immediately now and I started to lose a bit of weight so I've lost over a stone and would like to lose more - a few pounds maybe, but - other than that I haven't any real problems but all the symptoms have stopped. I stopped going to the loo and I'm not thirsty, just normal ... and I've been to the dietitian since in the hospital here and spent a good bit of time with her she sorta put me right as to what perhaps I should be doing as opposed to cutting out all my sugars.

$$
\text { (Male, focus group 4) }
$$

Family support's been great you know... wife and daughter - both for different reasons - one wants to lose the weight and one wants to stay off the chocolate so they are happy enough to go along with whatever is happening.

(Male, focus group 4)

\section{Discussion}

In general, barriers to lifestyle change received more prominence in discussions compared with facilitating factors. These patients had been diagnosed within the previous 24 months and so may not have felt fully competent in terms of self-management. Furthermore, in general terms, exercise was also discussed to a lesser extent compared with diet, perhaps reflecting the complexity of the dietary changes that patients are required to make, but maybe also indicating that physical activity receives less prominence in 
education activities or it may indicate a lack of interest in physical activity by the patients.

In this study, the overriding barriers that were discussed at length and across all focus groups were patients' concerns about changing well-established habits, coupled with a broadly negative perception of many aspects of their recommended diet and confusion about particular aspects of the diet. Patients appeared to feel overwhelmed by the number of changes they had to make to their diet. Although these factors have been reported previously (El-Kebbi et al., 1996; Savoca and Miller, 2001; Nthangeni et al., 2002; Vijan et al., 2005; Nagelkerk et al., 2006), patients in this study were recently diagnosed ( $<24$ months) and were on a steep learning curve with respect to diabetes self-management. Previous research in people with type 2 diabetes has highlighted that patients perceive making even moderate dietary changes to be more difficult than taking oral medications, and if their dietary regimen has been designed to promote weight loss, it is viewed as having a burden similar to that of twice daily injections (Vijan et al., 2005). Making dietary changes is a challenge not only for patients but also for HPs who must work towards making these changes appear less daunting, more manageable, more appealing and more achievable for patients.

Patients in this study, and many others (El-Kebbi et al., 1996; Savoca and Miller, 2001; Nagelkerk et al., 2006; Carbone et al., 2007), felt they were not as knowledgeable in some areas as they would have liked and felt confused about a lot of specific details (mainly quantity, type and amount of foods 'allowed'). Knowledge acquisition is a central aim of diabetes education programmes as it is fundamental to skills acquisition and enhancement of self-efficacy. It is noteworthy in this study that even though all of the participants had attended one or two group education session(s), knowledge and confusion about diet remained a major barrier for these patients. This has also been noted in many studies where most, or all, participants had attended a group education session (El-Kebbi et al., 1996; Savoca and Miller, 2001; Vijan et al., 2005; Nagelkerk et al., 2006). This may be related to both the amount of information that is conveyed to patients in a short period of time and the way in which it is conveyed. Repeated exposures to this new information in more manageable amounts may be required to build knowledge and confidence in this area. Provision of information in stages (which is the case in some, but not all, education programmes), alongside access to resources that can be used by patients in their own time and at their own pace outside of the formal education sessions, may be helpful. Such resources could be designed to assist with knowledge acquisition while also helping with self-monitoring and goal setting, thus helping to provide ongoing support to patients.

In relation to knowledge, one important issue was the fact that some patients felt they had been 'left in the dark' for months after being initially diagnosed as they received little or no information on what to eat during that period, so some 'didn't eat anything' and others made what they subsequently found were unsuitable changes. This is something that, to our knowledge, has not been highlighted previously and is worthy of exploration in other groups of patients and other health-care systems as it presents a significant gap that may need to be addressed.

Patients and HPs' views of physical activity were also explored; patients appeared to place much less emphasis on exercise when compared with diet as reflected in the extent of discussions around this topic, something that was also noted by Nagelkerk et al. (2006) in their study of patients with type 2 diabetes in a rural setting in America. In this study, the main barriers identified were in relation to having other co-morbidities and barriers related to the physical environment, both of which have been observed in previous research (Thomas et al., 2004; Dutton et al., 2005; Lawton et al., 2006). Physicians and nurses should consider these activity-related barriers alongside diet-related barriers in order to provide the most appropriate advice for each individual and ensure that advice to increase physical activity receives equal prominence to dietary advice; making changes towards a healthier activity pattern may help patients see positive effects quicker and thus assist with motivation.

Only a few barriers that have been frequently mentioned in other studies were not directly discussed in the present study, the most common one being poor communication with health-care providers. In many cases, this barrier refers to a lack of understanding by the health practitioner of cultural needs and financial situations of the patients (Quatromoni et al., 1994; Maillet et al., 1996; Savoca and Miller, 2001; 
West and McDowell, 2002; Dye et al., 2003; Lawton et al., 2005; Vijan et al., 2005; Devlin et al., 2006; Nagelkerk et al., 2006). The participants in this study attended a clinic in an area of lower socio-economic status and perhaps the health practitioners were cognizant of this fact and tailored their communications accordingly. Supporting this, cost was mentioned as a barrier by few HPs in the present study, and is frequently cited as a barrier in other studies (Quatromoni et al., 1994; El-Kebbi et al., 1996; Wdowik et al., 1997; Wang et al., 1999; Hwang and Bugeja, 2000; Kieffer et al., 2004; Vijan et al., 2005; Nagelkerk et al., 2006; Carbone et al., 2007; Simmons et al., 2007), but not was not raised as an issue by patients. Another barrier that has often been identified in other studies was the apparent timeconsuming nature of the diet (El-Kebbi et al., 1996; Savoca and Miller, 2001; Carbone et al., 2007). This barrier may have been less of a concern in the present study as most of the participants were retired, and, in the case of most of the men, responsibilities for food preparation rested with their partners.

A secondary aim of this study was to elicit the views of HPs and compare them with those of the patients as some evidence suggests that these two groups of individuals may have different views about diabetes self-care (Woodcock and Kinmonth, 2001; Nthangeni et al., 2002; Lawton et al., 2005; Carbone et al., 2007). In general, there was a high level of agreement between the barriers identified by patients and those identified by HPs; however, HPs did highlight a few barriers that the patients did not confirm. For example, patients expressed a much more negative perception of the new dietary regimen than HPs. Although HPs did note that many patients viewed the diet as boring or unappealing, they did not pick up on the related issues surrounding their preference for habitual foods rather than the new foods, the issues with recommended portion sizes and the difficulties patients felt with regard to having to follow a more regimented routine in general with respect to food. The patient groups were more homogeneous than the HPs (ie, all attended the same Centre), which may account for some of the differences in views expressed. Despite this, these appear to be critical issues that need to be considered when communicating with patients.
The limitations of this study must be borne in mind. The patients who participated in this study were a self-selected group of patients from a large regional diabetes clinic in Northern Ireland and so their views may not be representative of all recently diagnosed patients. More males participated than females, and although men may hold different views stark differences were not apparent in this study. The participant numbers were low, which may affect generalisability of the data, and the findings should be considered with this in mind; however, each group in this study provided consistent information and the researchers felt that saturation of ideas and themes had been reached after four focus groups. Even so, the possibility remains that further barriers may be elucidated given further exploration of this topic; many other interrelated factors that affect a patient's ability to selfmanage their condition such as psychological well-being (Peyrot et al., 2005) and depression (Vickers et al., 2006) were also not explored in this study. The small number of HPs interviewed may also affect generalisability of the results; however, care was taken to include a variety of HPs who are involved in the care of patients with type 2 diabetes.

\section{Conclusion}

Even against a background of diabetes education, patients recently diagnosed with type 2 diabetes discussed a wide range of barriers to selfmanagement of diet and physical activity, with facilitating factors receiving much less attention. HPs generally echoed the views of patients but perhaps underestimated the depth and breadth of the negative feelings that patients held towards the recommended dietary regimen. Support for diabetes self-management must try to make the required lifestyle changes more appealing and achievable and, in general, should also place more emphasis on physical activity. Consideration needs to be given as to how best to support people in the period between receiving their initial diagnosis and being offered diabetes education, which can often be a few months, as some patients feel that they are 'on their own' during this period. Qualitative research of this nature should be conducted on a regular basis in order to continue to prioritise 
areas for improved education, develop appropriate education tools and explore how these barriers and facilitators change over time.

\section{Practice implications}

The major challenge for HPs and those designing resources for people with type 2 diabetes remains communicating a large volume of information in a manageable form that will make lifestyle selfmanagement seem like a tangible goal. There is certainly scope for developing further resources to assist HPs in this regard; HPs have an important role to play in providing key support to patients, as illustrated in this study, but education resources that patients can use on an ongoing basis to supplement structured education programmes delivered in health-care settings are also required. Importantly, such resources may also be valuable to patients who experience a delay between their diagnosis and receipt of more structured dietary education.

\section{Acknowledgements}

The authors would like to thank the people with type 2 diabetes who volunteered to participate in this study. This study was supported by a research grant from The Sugar Bureau (United Kingdom). The funding source had no involvement in the research process and the authors are solely responsible for the results and conclusions herein. The authors have no competing interests to declare. Ethical statement: We confirm that all personal identifiers have been removed or disguised so the patients described are not identifiable and cannot be identified through the details of the story.

\section{References}

Barbour, R.S. and Kitzinger, J. 1999: Developing focus group research: politics, theory, and practice. London; Thousand Oaks, CA, USA: Sage Publications.

Carbone, E.T., Rosal, M.C., Torres, M.I., Goins, K.V. and Bermudez, O.I. 2007: Diabetes self-management: perspectives of Latino patients and their health care providers. Patient Education and Counseling 66, 202-10.

Devlin, H., Roberts, M., Okaya, A. and Xiong, Y.M. 2006: Our lives were healthier before: focus groups with African American, American Indian, Hispanic/Latino, and Hmong people with diabetes. Health Promotion Practice 7, 47-55.

Diabetes UK. 2010: Diabetes in the UK 2010: key statistics on diabetes. London: Diabetes UK.
Dutton, G.R., Johnson, J., Whitehead, D., Bodenlos, J.S. and Brantley, P.J. 2005: Barriers to physical activity among predominantly low-income African-American patients with type 2 diabetes. Diabetes Care 28, 1209-210.

Dye, C.J., Haley-Zitlin, V. and Willoughby, D. 2003: Insights from older adults with type 2 diabetes: making dietary and exercise changes. Diabetes Education 29, 116-27.

El-Kebbi, I.M., Bacha, G.A., Ziemer, D.C., Musey, V.C., Gallina, D.L., Dunbar, V. and Phillips, L.S. 1996: Diabetes in urban African Americans. V. Use of discussion groups to identify barriers to dietary therapy among low-income individuals with non-insulin-dependent diabetes mellitus. Diabetes Education 22, 488-92.

Gregory, S. 2010: Narrative approaches to healthcare research. Journal of Therapy and Rehabilitation 17, 630-36.

Hayes, C., Herbert, M., Marrero, D., Martins, C.L. and Muchnick, S. 2008: Diabetes and exercise. Diabetes Education 34, 37-40.

Hsu, M.Y. and McCormack, B. 2012: Using narrative inquiry with older people to inform practice and service developments. Journal of Clinical Nursing 21, 841-49.

Hwang, S.W. and Bugeja, A.L. 2000: Barriers to appropriate diabetes management among homeless people in Toronto. Canadian Medical Association Journal 163, 161-65.

Kieffer, E.C., Willis, S.K., Odoms-Young, A.M., Guzmaz, J.R., Allen, A.J., Two Feathers, J. and Loveluck, J. 2004: Reducing disparities in diabetes among AfricanAmerican and Latino residents of Detroit: the essential role of community planning focus groups. Ethnicity and Disease 14, (Suppl 1), S27-37.

Krueger, R.A. and Casey, M.A. 2000: Focus groups: a practical guide for applied research, third edition. Thousand Oaks, CA, USA: Sage Publications.

Kulkarni, K. 2006: Diets do not fail: the success of medical nutrition therapy in patients with diabetes. Endocrine Practice 12, (Suppl 1), 121-23.

Lawton, J., Ahmad, N., Hanna, L., Douglas, M. and Hallowell, N. 2006: 'I can't do any serious exercise': barriers to physical activity amongst people of Pakistani and Indian origin with Type 2 diabetes. Health Education Research 21, 43-54.

Lawton, J., Parry, O., Peel, E. and Douglas, M. 2005: Diabetes service provision: a qualitative study of newly diagnosed Type 2 diabetes patients' experiences and views. Diabetic Medicine 22, 1246-251.

Maillet, N.A., D'Eramo Melkus, G. and Spollett, G. 1996: Using focus groups to characterize the health beliefs and practices of black women with non-insulin-dependent diabetes. Diabetes Education 22, 39-46.

Nagelkerk, J., Reick, K. and Meengs, L. 2006: Perceived barriers and effective strategies to diabetes self-management. Journal of Advanced Nursing 54, 151-58.

National Institute for Health and Clinical Excellence (NICE) 2008: Type 2 diabetes: the management of type 2 diabetes (update). London: NICE.

Nthangeni, G., Steyn, N.P., Alberts, M., Steyn, K., Levitt, N.S., Laubscher, R., Bourne, L., Dick, J. and Temple, N. 
2002: Dietary intake and barriers to dietary compliance in black type 2 diabetic patients attending primary healthcare services. Public Health Nutrition 5, 329-38.

Pendleton, L., House, W.C. and Parker, L.E. 1987: Physicians' and patients' views of problems of compliance with diabetes regimens. Public Health Reports 102, 21-26.

Peyrot, M., Rubin, R.R., Lauritzen, T., Snoek, F.J., Matthews, D.R. and Skovlund, S.E. 2005: Psychosocial problems and barriers to improved diabetes management: results of the Cross-National Diabetes Attitudes, Wishes and Needs (DAWN) Study. Diabetic Medicine 22, 1379-85.

Quatromoni, P.A., Milbauer, M., Posner, B.M., Carballeira, N.P., Brunt, M. and Chipkin, S.R. 1994: Use of focus groups to explore nutrition practices and health beliefs of urban Caribbean Latinos with diabetes. Diabetes Care 17, 869-73.

Savoca, M. and Miller, C. 2001: Food selection and eating patterns: themes found among people with type 2 diabetes mellitus. Journal of Nutrition Education 33, 224-33.

Shultz, J.A., Sprague, M.A., Branen, L.J. and Lambeth, S. 2001: A comparison of views of individuals with type 2 diabetes mellitus and diabetes educators about barriers to diet and exercise. Journal of Health Communication 6, 99-115.

Simmons, D., Lillis, S., Swan, J. and Haar, J. 2007: Discordance in perceptions of barriers to diabetes care between patients and primary care and secondary care. Diabetes Care 30, 490-95.
Sullivan, E.D. and Joseph, D.H. 1998: Struggling with behavior changes: a special case for clients with diabetes. Diabetes Education 24, 72-77.

Thomas, N., Alder, E. and Leese, G.P. 2004: Barriers to physical activity in patients with diabetes. Postgraduate Medical Journal 80, 287-91.

Vickers, K.S., Nies, M.A., Patten, C.A., Dierkhising, R. and Smith, S.A. 2006: Patients with diabetes and depression may need additional support for exercise. American Journal of Health Behaviour 30, 353-62.

Vijan, S., Stuart, N.S., Fitzgerald, J.T., Ronis, D.L., Hayward, R.A., Slater, S. and Hofer, T.P. 2005: Barriers to following dietary recommendations in type 2 diabetes. Diabetic Medicine 22, 32-38.

Wang, C.Y., Abbott, L., Goodbody, A.K., Hui, W.T. and Rausch, C. 1999: Development of a community-based diabetes management program for Pacific Islanders. Diabetes Education 25, 738-46.

Wdowik, M.J., Kendall, P.A. and Harris, M.A. 1997: College students with diabetes: using focus groups and interviews to determine psychosocial issues and barriers to control. Diabetes Education 23, 558-62.

West, C. and McDowell, J. 2002: The distress experienced by people with type 2 diabetes. British Journal of Community Nursing 7, 606-13.

Woodcock, A. and Kinmonth, A.L. 2001: Patient concerns in their first year with type 2 diabetes: patient and practice nurse views. Patient Education Counseling 42, 257-70. 